\title{
Measuring Tree Height with Remote Sensing-A Comparison of Photogrammetric and LiDAR Data with Different Field Measurements
}

\author{
Selina Ganz *, Yannek Käber ${ }^{\mathbb{D}}$ and Petra Adler \\ Forstliche Versuchs- und Forschungsanstalt Baden-Württemberg (FVA), Wonnhaldestraße 4, \\ 79100 Freiburg, Germany \\ * Correspondence: Selina.Ganz@Forst.bwl.de; Tel.: +49-761-4018-285
}

Received: 9 July 2019; Accepted: 14 August 2019; Published: 16 August 2019

check for updates

\begin{abstract}
We contribute to a better understanding of different remote sensing techniques for tree height estimation by comparing several techniques to both direct and indirect field measurements. From these comparisons, factors influencing the accuracy of reliable tree height measurements were identified. Different remote sensing methods were applied on the same test site, varying the factors sensor type, platform, and flight parameters. We implemented light detection and ranging (LiDAR) and photogrammetric aerial images received from unmanned aerial vehicles (UAV), gyrocopter, and aircraft. Field measurements were carried out indirectly using a Vertex clinometer and directly after felling using a tape measure on tree trunks. Indirect measurements resulted in an RMSE of $1.02 \mathrm{~m}$ and tend to underestimate tree height with a systematic error of $-0.66 \mathrm{~m}$. For the derivation of tree height, the results varied from an RMSE of $0.36 \mathrm{~m}$ for UAV-LiDAR data to $2.89 \mathrm{~m}$ for photogrammetric data acquired by an aircraft. Measurements derived from LiDAR data resulted in higher tree heights, while measurements from photogrammetric data tended to be lower than field measurements. When absolute orientation was appropriate, measurements from UAV-Camera were as reliable as those from UAV-LiDAR. With low flight altitudes, small camera lens angles, and an accurate orientation, higher accuracies for the estimation of individual tree heights could be achieved. The study showed that remote sensing measurements of tree height can be more accurate than traditional triangulation techniques if the aforementioned conditions are fulfilled.
\end{abstract}

Keywords: remote sensing; individual tree height; forest inventory; digital aerial photogrammetry; airborne laser scanning; UAV; gyrocopter; data acquisition parameters

\section{Introduction}

Individual tree height is a fundamental forest inventory parameter [1] and is often used for the estimation of forest growth, biomass, carbon stock and site productivity [2]. Traditional methods for measuring the height of standing trees involve the visual assessment of the treetop and the use of basic trigonometric calculations [3]. However, indirect field-based measurements at the single tree level are expensive, time-consuming and often not feasible for large areas or for high temporal resolutions [4,5]. To improve forest management, there is a need to have easily updateable inventories with spatially and temporally accurate data at an appropriate cost [1]. Within the last decades, various remote-sensing-based methods have been developed and studied. Remote sensing has the potential to provide consistent, reproducible and up-to-date information on various forest parameters in order to make inventories more efficient [6]. Previous studies mostly applied a specific remote sensing system to a single area and demonstrated how remote sensing can be used for quick assessment of forests at large spatial scales (see, e.g., [7-16]). Nevertheless, comparing novel remote sensing 
methods for measuring tree height usually involves a high degree of uncertainty. The remote sensing systems, data acquisition parameters, forest characteristics and meteorological conditions such as cloud coverage, illumination, season of scan used in these studies vary. As such, it is difficult to transfer measurement errors between the applied methods. The general comparability of measurement methods is compromised as study areas differ in terms of tree species present, forest type or stand characteristics such as stand age or tree density. Furthermore, remote sensing systems such as platform and sensor as well as data acquisition parameters such as flight height and weather conditions vary between studies. A further difficulty arises in that the reference measurements can be derived from different methods at the stand or single tree level (see, e.g., $[7,8,13])$. These differences and variations between studies make comparisons of remote-sensing-based measurements difficult and in some cases simply not feasible. Ref. [17] illustrated the numerous different parameters used by different studies to predict forest inventory attributes. Standardization and benchmarking studies focusing on data acquisition parameters are crucial to detailing best practice approaches [17]. Furthermore, one aspect common among most studies is that they implement traditional field-based measurements for validation [18]. These field surveys have also measurement errors, but the level of error is often not declared [19]. Until now, only a few studies carried out direct measurements of the length of tree trunks to verify remote sensing tree height estimates [18]. Ref. [19] assessed tree height estimation using airborne LiDAR and field-based methods by harvesting trees for validation. They observed that the LiDAR-derived tree heights were closer to direct tree heights than traditional field-based measurements. Ref. [18] compared UAV photogrammetric tree height measurements with indirect and direct field-based surveys. The authors found that photogrammetric measurements resulted in a similar level of error to that of the field-based tree height measurements.

In this study, we contribute to a better understanding of different remote sensing systems for tree height estimation by applying several methods and compare them to direct and indirect field measurements. We applied several remote sensing methods to the same test site over two consecutive years and varied the sensor type, platform, and flight parameters. We used light detection and ranging (LiDAR) data and photogrammetric aerial images received from unmanned aerial vehicles (UAV), gyrocopters and aircraft. Remote sensing measurements of tree height were then compared to field measurements made indirectly (via visual assessment of standing trees) and directly (using a measuring tape on tree trunks after felling). With comparison to direct field measurements, we were able to demonstrate the potential of several sensors and platforms with greater certainty, including benchmarking of acquisition parameters.

The application of the different systems under comparable conditions allowed us to set out the following objectives: (1) Assess the accuracy of traditional field-based tree height measurements (2) compare the accuracy of individual tree height measurements derived from photogrammetric or LiDAR data against direct measurements (3) based on these comparisons, factors influencing the accuracy of tree height derivation are to be identified.

\section{Materials and Methods}

\subsection{Study Area}

The study area consisted of an even-aged 50-year-old Douglas fir (Pseudotsuga menziesii (Mirb.) Franco) stand in the Black Forest in Baden-Württemberg, Germany ( $\left.47^{\circ} 42^{\prime} \mathrm{N} 7^{\circ} 42^{\prime} \mathrm{E}\right)$. That stand was part of a stand spacing experiment of the department of forest growth of the Forest Research Institute Baden-Württemberg (FVA). A description of the stand spacing experiment can be found in ref. [20]. The stand has a size of 2 ha and contains six plots, each with an area of 0.14 to 0.16 ha. This results in an actual research area of 1 ha because spaces between plots are only considered in terms of neighborhood relations. The stand is located on a slight and regular slope (approx. $15^{\circ}$ ) inclined to the south-west. The crown closure varies between overlapping crowns and small gaps with the maximum size of small crowns. At the time of the first survey (15 March 2018), the mean parameters of the forest stand 
calculated from the six fully inventoried plots were 234.4 trees per ha, a basal area of $43.45 \mathrm{~m}^{2}$ per ha and a standing volume of $452 \mathrm{~m}^{3}$ per ha. The homogeneous stand showed no natural regeneration and hardly any shrubs or other low vegetation. The trees within the plots had a mean diameter at breast height of $40.9 \mathrm{~cm}( \pm 13.5 \mathrm{~cm}$, standard deviation $(\mathrm{SD}))$ in a value range from 13.8 to $63.9 \mathrm{~cm}$. We selected 30 trees, which cover the range of diameters present in the stand. These trees were also representative for the variation in branch number and crown size present in the stand. The average height of the selected trees was $33.9 \mathrm{~m}( \pm 2.5 \mathrm{~m}, \mathrm{SD})$ in 2017 and $34.4 \mathrm{~m}( \pm 3.2 \mathrm{~m}, \mathrm{SD})$ in 2018 (Figure 1).

2017

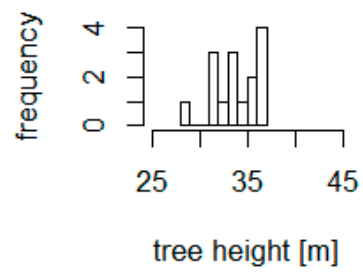

2018

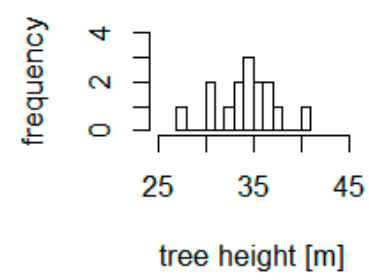

Figure 1. Tree heights of the selected trees in 2017 and 2018, respectively.

\subsection{Field Data Collection}

Data collection in the field took place in June 2017 and March 2018. Fifteen trees were assessed per time period. The heights of the test trees were initially measured indirectly on standing trees using the ultrasonic-based device Vertex IV (Haglöf Sweden AB). A Vertex clinometer is one of the most common instruments for measuring tree height [21]. After the Vertex was paired and calibrated with its transponder, all measurements were performed by the same operator. Tree length was then measured after felling, using a tape measure on the trunk of the felled tree. The timing of data collection in the field was adapted to the flights for remote sensing data, such that time laps between measurements, felling, and flights were short.

\subsection{Remote Sensing Data Acquisition}

In summer 2017 and spring 2018, different flights were performed using several different remote sensing systems. UAVs recorded the study area using a LiDAR sensor and an RGB camera. Additionally, a gyrocopter took aerial images of the study site from two different flight altitudes. The data with the lowest spatial resolution was provided by an official aircraft image flight (photogrammetric flight) of the state agency of spatial information and rural development of Baden-Württemberg (LGL) from 2016 [22]. An overview of the performed flights (UAV-LiDAR 2017, UAV-LiDAR 2018, UAV-Camera 2017, UAV-Camera 2018, Gyrocopter $2 \mathrm{~cm}$, Gyrocopter $5 \mathrm{~cm}$ ) and the aircraft image flight of 2016 is shown in Table 1. The laser flights have been performed by a HEIGHTECH HT-8 (2017) and a Tarot X6 (2018). The UAVs were equipped with the laser scanner Mapper I from YellowScan. The LiDAR sensor used Multi-Echo technology and was able to capture three echoes per laser beam (the first, middle and last return). For both UAV image flights, a Sony Alpha 7R camera with a focal length of $35 \mathrm{~mm}$ was used. The three bands red, green and blue (RGB) were recorded at a radiometric resolution of 8 bit. The aerial images had a mean ground sampling distance (GSD) of $1 \mathrm{~cm}$. The flights carried out by gyrocopter (AutoGyro MTOsport D-MDOB) used a NIKON D800E camera with a focal length of $85 \mathrm{~mm}$. The radiometric resolution was 8 bit and the GSD ranged—depending on flight altitude-from 2 to $5 \mathrm{~cm}$. The aircraft image flight was performed using an UltraCam XP with a focal length of $100.5 \mathrm{~mm}$. Aerial images from this camera contained the four bands red, blue, green, and infrared (RGBI) at a radiometric resolution of 16 bit. The GSD was $20 \mathrm{~cm}$. The orientation of the image and LiDAR data was registered via the GNSS (Global Navigation and Satellite System) units built into the systems. Ground control points (GCPs) were additionally used for image flights. For the gyrocopter flights, 14 and 12 GCPs were used for the GSD of 5 and $2 \mathrm{~cm}$, respectively. During data acquisition by UAV, because of poor visibility of the ground in 2017, only 4 GCPs were used, which were not 
optimally distributed over the area of the flight. In 2018, 12 well distributed GCPs could be used. The aerial images from the UAV and gyrocopter flights were processed using Agisoft Photoscan Version 1.4.2 and 1.3.4 to produce photogrammetric point clouds and orthoimages. The aerial images from the aircraft image flight were processed to obtain point clouds and orthoimages with a GSD of 20 and $50 \mathrm{~cm}$ using the software SURE Version 2.1.0.33.

Table 1. An overview of the data collected via UAVs, gyrocopter and aircraft.

\begin{tabular}{ccccccc}
\hline Platform & $\begin{array}{c}\text { Type of } \\
\text { System }\end{array}$ & $\begin{array}{c}\text { GSD } \\
(\mathbf{c m})\end{array}$ & $\begin{array}{c}\text { Date of } \\
\text { Acquisition }\end{array}$ & $\begin{array}{c}\text { Altitude above } \\
\text { Ground }\end{array}$ & Overlap & $\begin{array}{c}\text { Point Density } \\
\text { (points } / \mathbf{m}^{\mathbf{2}} \text { ) }\end{array}$ \\
\hline Aircraft & Camera & 20 & 10.07 .2016 & $2700-2750 \mathrm{~m}$ & $68 \% / 40 \%$ & 25 \\
Aircraft & Camera & 50 & 10.07 .2016 & $2700-2750 \mathrm{~m}$ & $68 \% / 40 \%$ & 4 \\
Gyrocopter & Camera & 2 & 20.06 .2017 & $\sim 300 \mathrm{~m}$ & $85 \% / 70 \%$ & 502 \\
Gyrocopter & Camera & 5 & 20.06 .2017 & $\sim 800 \mathrm{~m}$ & $90 \% / 70 \%$ & 66 \\
UAV & Camera & 1 & 15.03 .2018 & $50-60 \mathrm{~m}$ & $60 \%-70 \%$ & 620 \\
UAV & Camera & 1 & $19.06-20.06 .2017$ & $80-100 \mathrm{~m}$ & $50 \%$ & 350 \\
UAV & LiDAR & - & $19.06-20.06 .2017$ & $80-100 \mathrm{~m}$ & $80 \% / 80 \%$ & 1690 \\
UAV & LiDAR & - & 15.03 .2018 & $80-100 \mathrm{~m}$ & $80 \% / 80 \%$ & 2118 \\
\hline
\end{tabular}

The LiDAR point clouds consisted of $75.5 \%$ and $67.6 \%$ first returns, $21.5 \%$ and $26.7 \%$ middle returns and 3.0\% and 5.7\% last returns in 2017 and 2018, respectively. The penetration rate (ground points divided by all points of the point cloud) was 3.0\% in 2017 and $13.5 \%$ in 2018. Figure 2 shows an example of the point clouds of a segmented tree crown gathered using different methods. It visualizes that higher point densities include more details of the tree crown. It also shows, that the photogrammetric point clouds describe the surface of the crown, while the LiDAR point clouds describe the structure of the tree crown from the top (high point density) to the ground (lower point density).

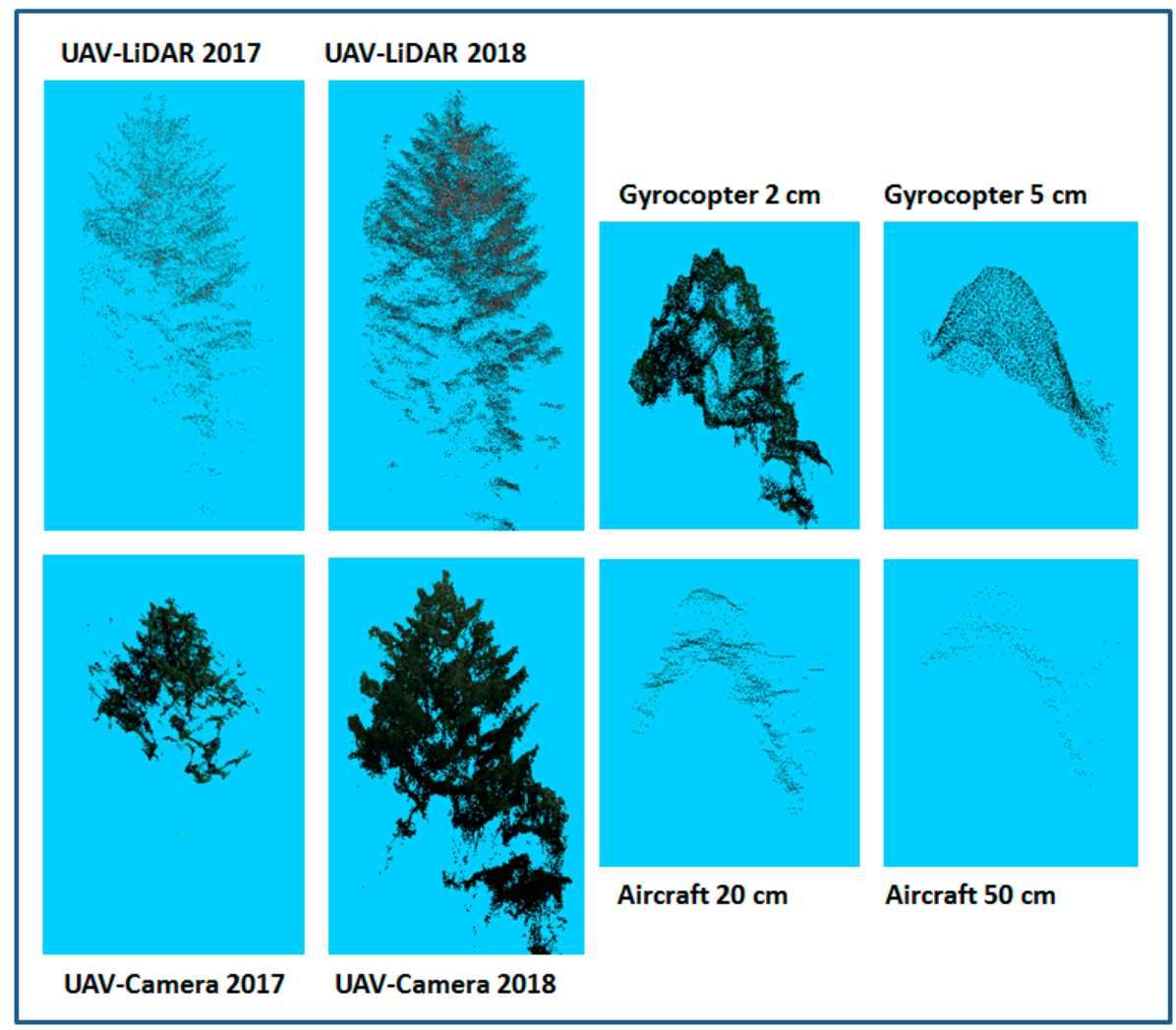

Figure 2. Comparison of the point clouds obtained from all remote sensing datasets. All point clouds show a single tree crown from the same perspective. 


\subsection{Computation of Individual Tree Heights}

Digital surface models (DSM), which were generated from photogrammetric point clouds as well as from LiDAR data, served as the basis for deriving individual tree heights. A DSM was generated using the $R$ package lidR version 1.5.0 [23]. The Z-value of the highest point per pixel was returned. Empty pixels were interpolated using a combination of the k-nearest-neighbor approach and inverse distance weighting. For the UAV and gyrocopter data, a DSM with a GSD of $10 \mathrm{~cm}$ was created, whereas the point clouds of the aircraft image flight resulted in a DSM with a GSD of 20 and $50 \mathrm{~cm}$. In order to derive individual tree heights, the determination of individual trees is necessary. Consequently, all pixels of an image which belong to an individual tree crown must be isolated from other pixels. We used a Watershed algorithm for segmentation, which detected $53.5 \%$ (Aircraft $50 \mathrm{~cm}$ ) - 73.0\% (Gyrocopter $2 \mathrm{~cm}$ ) of the trees within the six plots. Because not all test trees could be detected automatically with this segmentation, we delineated the tree crowns manually on the orthoimages and DSM. The highest DSM value within these segments was defined as treetop. In order to obtain tree height, the difference between the highest DSM value and the corresponding terrain height was calculated. For the normalization of photogrammetric point clouds, an Airborne Laser Scanning (ALS)-derived DTM is always required [24], since photogrammetric DTMs from forest areas are often inaccurate and are not recommended [17]. Therefore, the digital terrain model (DTM) of the LGL calculated from LiDAR data with a GSD of $1 \mathrm{~m}$ was used [25]. To analyze the influence of GCPs, the resulting DSM of the dataset UAV-Camera 2017 was calculated with and without GCPs. Where GCPs were not implemented we aimed to improve the DSM retrospectively. For this purpose, on manual set ground points, the difference between DSM and DTM value was calculated. These values were interpolated to a surface via polynomial regression. With this surface, the elevation of the DSM was corrected.

\subsection{Statistical Analysis}

For the statistical analysis, we compared the tree heights derived from remote sensing datasets and from indirect measurements before harvesting to the direct measurements of the felled trees, used for validation. Note that as well as the indirect measurement with Vertex or remote sensing data and direct measurements of felled trees are referred to as tree height even if the latter actually is the tree length. The accuracy assessment was carried out by calculating the root mean squared error (RMSE), relative RMSE (RMSE\%), mean error (ME) and the coefficient of determination R-squared $\left(R^{2}\right)$. RMSE determines the total error, whereas ME indicates systematic error. R-squared is a goodness-of-fit measurement for linear models. Data processing and analysis were carried out using the R programming language [20].

\section{Results}

An overview of descriptive statistics is displayed in Table 2. Figure 3 shows the distribution of the measured tree heights of the different datasets as boxplots. It should be noted that there is a temporal discrepancy of 11 and 20 months between the aircraft image flight in 2016 and the field measurements in 2017 and 2018, respectively. The collection of branch whorl measurements showed an average distance of $0.5 \mathrm{~m}$ between whorls and a maximum of $1.4 \mathrm{~m}$ between whorls for the last five years. Under the assumption that a new whorl was created each year, annual height growth of ca. $50 \mathrm{~cm}$ and in extreme cases up to $1.4 \mathrm{~m}$ can be assumed. Therefore, a mean error of up to $1.4 \mathrm{~m}$ should be tolerated in the results of the aircraft aerial photographs. 
Table 2. Summary statistics of tree height $(n=15)$ by field measurements and remote sensing.

\begin{tabular}{cccccccc}
\hline Platform & $\begin{array}{c}\text { Type of } \\
\text { System }\end{array}$ & GSD (cm) & $\begin{array}{c}\text { Year of } \\
\text { Acquisition }\end{array}$ & $\begin{array}{c}\text { Min } \\
(\mathbf{m})\end{array}$ & $\begin{array}{c}\text { Mean } \\
(\mathbf{m})\end{array}$ & $\begin{array}{c}\text { Max } \\
(\mathbf{m})\end{array}$ & $\begin{array}{c}\text { SD } \\
(\mathbf{m})\end{array}$ \\
\hline Aircraft & Camera & 20 & 2016 & 27.96 & 32.22 & 35.47 & 2.13 \\
Aircraft & Camera & 50 & 2016 & 27.75 & 31.2 & 34.11 & 1.95 \\
Gyrocopter & Camera & 2 & 2017 & 28.2 & 33.48 & 37.05 & 2.37 \\
Gyrocopter & Camera & 5 & 2017 & 28.49 & 32.64 & 35.8 & 2.12 \\
UAV & Camera & 1 & 2017 & 27.57 & 32.91 & 35.59 & 2.33 \\
UAV & Camera & 1 & 2018 & 27.58 & 34.2 & 41.27 & 3.55 \\
UAV & LiDAR & - & 2017 & 28.31 & 34.02 & 37.3 & 2.46 \\
UAV & LiDAR & - & 2018 & 27.76 & 34.85 & 41.95 & 3.53 \\
Measuring tape & manually & - & 2017 & 28.3 & 33.93 & 37 & 2.46 \\
Measuring tape & manually & - & 2018 & 27.9 & 34.41 & 40.8 & 3.22 \\
Vertex & manually & - & 2017 & 27.9 & 32.85 & 36 & 2.38 \\
Vertex & manually & - & 2018 & 26.8 & 34.17 & 39.6 & 3.13 \\
\hline
\end{tabular}

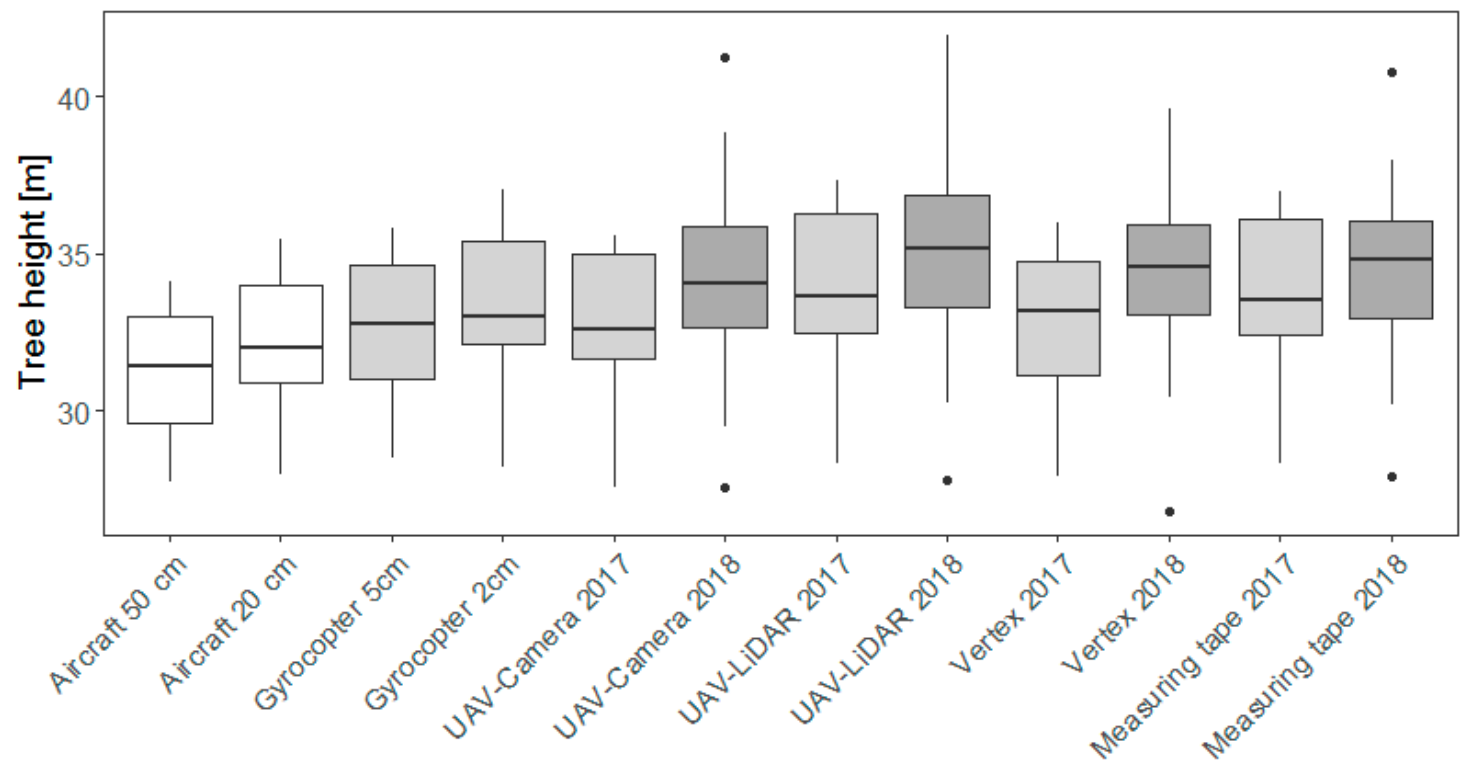

Acquisition year 追 2016 穴 2017 追 2018

Figure 3. Boxplot analysis of tree heights $(n=15)$ derived from field measurements and remote sensing.

\subsection{Accuracy Assessment}

The direct measurement of the length of felled trees using a measuring tape was assumed as the most accurate measurement in the field and was used for validation. Average tree height derived from this method was $33.93 \mathrm{~m}$ in 2017 and $34.41 \mathrm{~m}$ in 2018. Average tree height measured indirectly was 32.85 and $34.17 \mathrm{~m}$ for 2017 and 2018, respectively. The regression between indirect measurements via Vertex and tape measurements resulted in an $R^{2}$ of 0.92 , which indicates a very strong correlation between these two measurement methods (see Figure 4). Assuming that measurements by tape represent the real tree height, an RMSE of $1.02 \mathrm{~m}$ was obtained for the indirect measurement via Vertex with a mean error of $-0.66 \mathrm{~m}$ (see Table 3 ). 


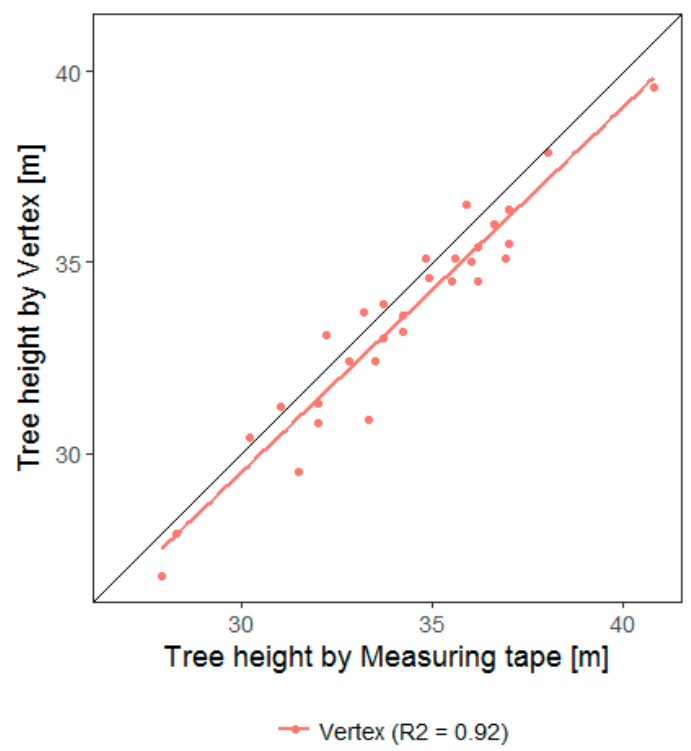

Figure 4. Regression analysis between tree height recorded using Vertex (indirect) and tree height recorded using a measuring tape (direct). The black line represents a 1:1 correlation between the two measurement techniques.

Table 3. Overview of the statistical results of the remote sensing datasets and the measurements via Vertex. Tree heights recorded via measuring tape were assumed as the real tree heights.

\begin{tabular}{cccccc}
\hline Platform & $\begin{array}{c}\text { Type of } \\
\text { System }\end{array}$ & GSD (cm) & $\begin{array}{c}\text { Year of } \\
\text { Acquisition }\end{array}$ & RMSE (m) & $\begin{array}{c}\text { ME } \\
(\mathbf{m})\end{array}$ \\
\hline Aircraft & Camera & 20 & 2016 & 1.86 & -1.63 \\
Aircraft & Camera & 50 & 2016 & 2.89 & -2.71 \\
Gyrocopter & Camera & 2 & 2017 & 0.68 & -0.44 \\
Gyrocopter & Camera & 5 & 2017 & 1.44 & -1.29 \\
UAV & Camera & 1 & 2017 & 1.09 & -1.03 \\
UAV & Camera & 1 & 2018 & 0.49 & -0.18 \\
UAV & LiDAR & - & 2017 & 0.36 & 0.13 \\
UAV & LiDAR & - & 2018 & 0.49 & 0.3 \\
Vertex & manually & - & $2017 / 2018$ & 1.02 & -0.66 \\
\hline
\end{tabular}

Figure 5 shows the offset of the different remote sensing datasets and the Vertex measurement compared to the tape measurements. The results varied from an RMSE of $0.36 \mathrm{~m}$ (RMSE\%: 1.05) for UAV-LiDAR 2017 to $2.89 \mathrm{~m}$ (RMSE\%: 8.46) for aircraft $50 \mathrm{~cm}$ (see Table 3). The comparison of the different sensors and platforms showed that the UAV-LiDAR 2017 and 2018 had the most accurate results, followed by UAV-Camera 2018 and Gyrocopter $2 \mathrm{~cm}$. The best results all had an RMSE $<0.7 \mathrm{~m}$. UAV-Camera 2017, Gyrocopter $5 \mathrm{~cm}$ and the aircraft aerial images resulted in an RMSE $>1.09 \mathrm{~m}$ with a $\mathrm{ME}<-1 \mathrm{~m}$. The LiDAR data derived higher tree heights than the field measurements, while the photogrammetric data tended to be lower than field measurements. Of all measurement methods, Vertex showed the greatest variation in accuracy. Due to the time difference between the aircraft aerial flight at the beginning of July 2016 and the field measurements at the end of June 2017, the results of the aircraft aerial photographs must be interpreted with care. In addition to the $1.4 \mathrm{~m}$ that should be tolerated because of the annual height growth, tree height derived from aircraft aerial photographs still contained errors of 1-2 m. 


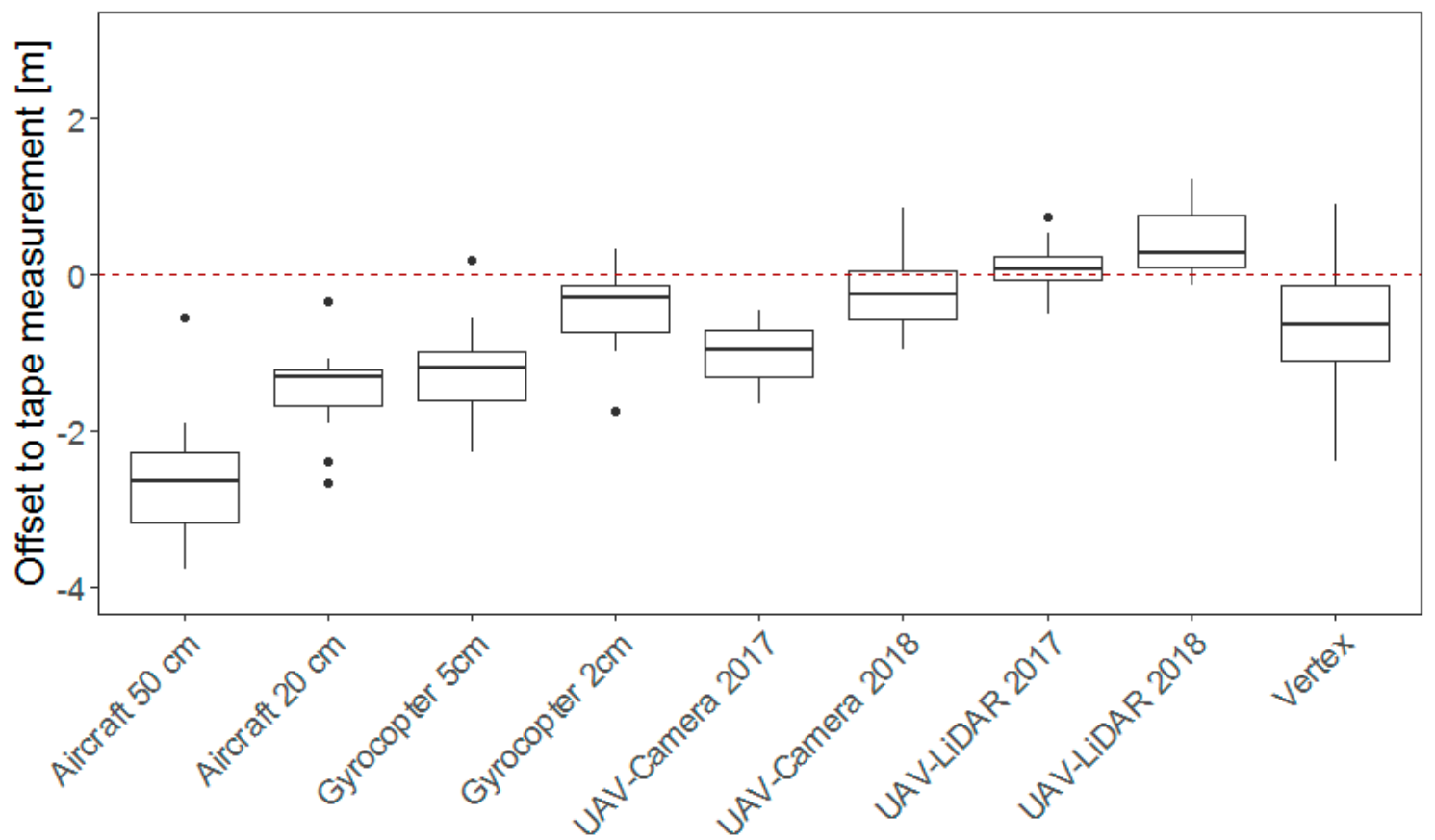

Figure 5. Boxplot analysis for the remote sensing datasets and the terrestrial measurement via Vertex. Tree heights recorded via measuring tape were assumed as the real tree heights.

All regressions were significant $(p<0.001)$ and gave a very good fit $\left(R^{2}>0.86\right)$, see Figure 6 and Table 4 . The models obtained through regression analysis showed approximately no difference between the derivations of tree height for trees of different sizes, meaning that there was no over- or underestimation of smaller or taller trees. The differences observed between the models lay in the magnitude of the over- or underestimations and the $R^{2}$ value. The UAV data had the highest $R^{2}$ values, with an almost perfect fit $\left(R^{2}>0.97\right)$, followed by the gyrocopter datasets $\left(R^{2}>0.94\right)$ and finally by the datasets of the aircraft image flights $\left(R^{2}>0.86\right)$. As such, the models from UAV and gyrocopter data fitted better than the Vertex measurements $\left(R^{2}=0.92\right)$.
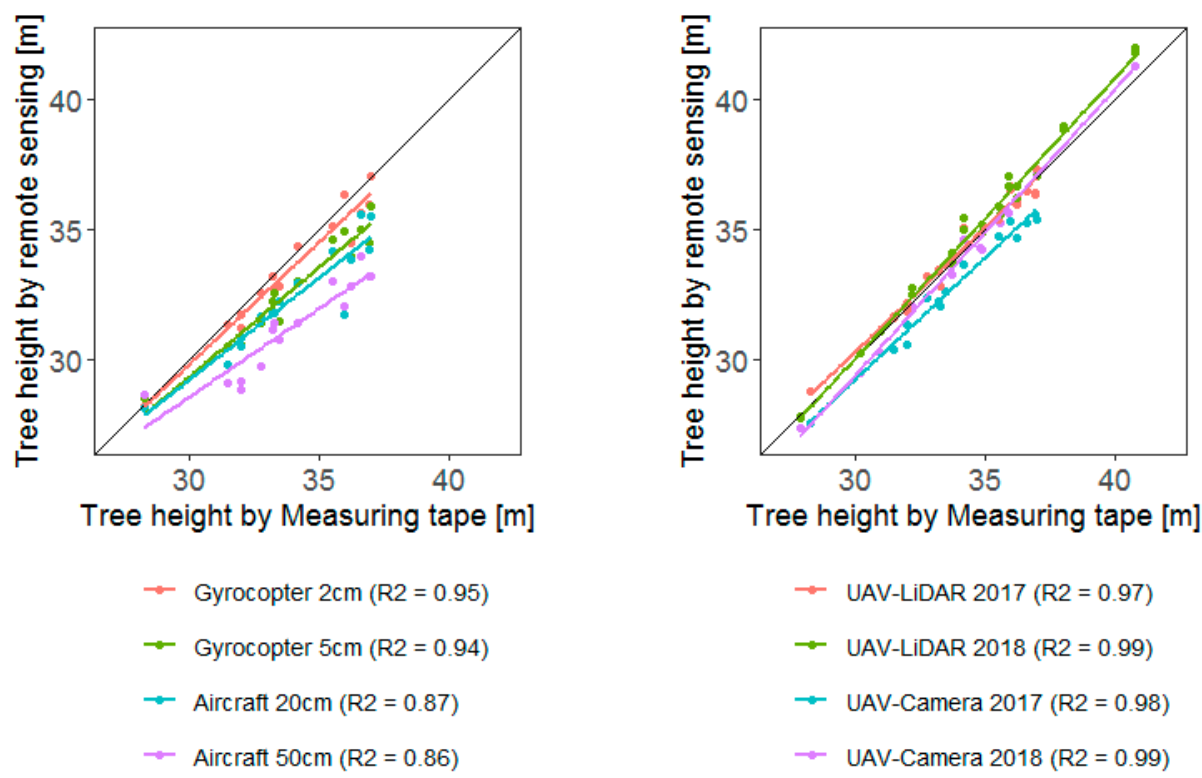

Figure 6. Regression analysis for the remote sensing datasets. Tree heights recorded via measuring tape were assumed as the real tree heights. Points represent individual measurements, the colored lines represent the regressions and the black line represents a 1:1 correlation. 
Table 4. Overview of the linear models for estimating tree height $(y=$ tree height by measuring tape, $x=$ tree height by remote sensing).

\begin{tabular}{cccccc}
\hline Platform & $\begin{array}{c}\text { Type of } \\
\text { System }\end{array}$ & $\begin{array}{c}\text { GSD } \\
(\mathbf{c m})\end{array}$ & $\begin{array}{c}\text { Year of } \\
\text { Acquisition }\end{array}$ & Linear Model & $\boldsymbol{R}^{\mathbf{2}}$ \\
\hline Aircraft & Camera & 20 & 2016 & $y=0.78 x+5.64$ & 0.87 \\
Aircraft & Camera & 50 & 2016 & $y=0.86 x+8.14$ & 0.86 \\
Gyrocopter & Camera & 2 & 2017 & $y=0.94 x+1.59$ & 0.95 \\
Gyrocopter & Camera & 5 & 2017 & $y=0.84 x+4.09$ & 0.94 \\
UAV & Camera & 1 & 2017 & $y=0.94 x+1.16$ & 0.98 \\
UAV & Camera & 1 & 2018 & $y=1.10 x-3.61$ & 0.99 \\
UAV & LiDAR & - & 2017 & $y=0.95 x+1.62$ & 0.97 \\
UAV & LiDAR & - & 2018 & $y=1.08 x-2.31$ & 0.99 \\
Vertex & manually & - & $2017 / 2018$ & $y=0.96 x+0.82$ & 0.92 \\
\hline
\end{tabular}

\subsection{Analyzing the Influence of Orientation Quality for Tree Height Derivation}

One aim of the study was to analyze the influence of data acquisition parameters, such as orientation quality in order to obtain reliable tree height measurements. With the dataset UAV-Camera 2017, having presumably an insufficient orientation quality, we analyzed the influence of the usage of GCPs and the influence of correcting a DSM retrospectively on the accuracy of tree height derivation. With the usage of GCPs and with the original DSM (no retrospective correction), the dataset UAV-Camera 2017 achieved an RMSE of $1.09 \mathrm{~m}$ and a ME $1.03 \mathrm{~m}$ (see Table 3). Without the usage of GCPs, the RMSE was $0.65 \mathrm{~m}$ for the corrected DSM and $4.80 \mathrm{~m}$ for the original DSM (no retrospective correction), whereas the ME was $0.51 \mathrm{~m}$ with correction of the DSM and $4.79 \mathrm{~m}$ without. Figure 7 shows the offset of the tape measurement to various tree height calculations with UAV-Camera 2017.

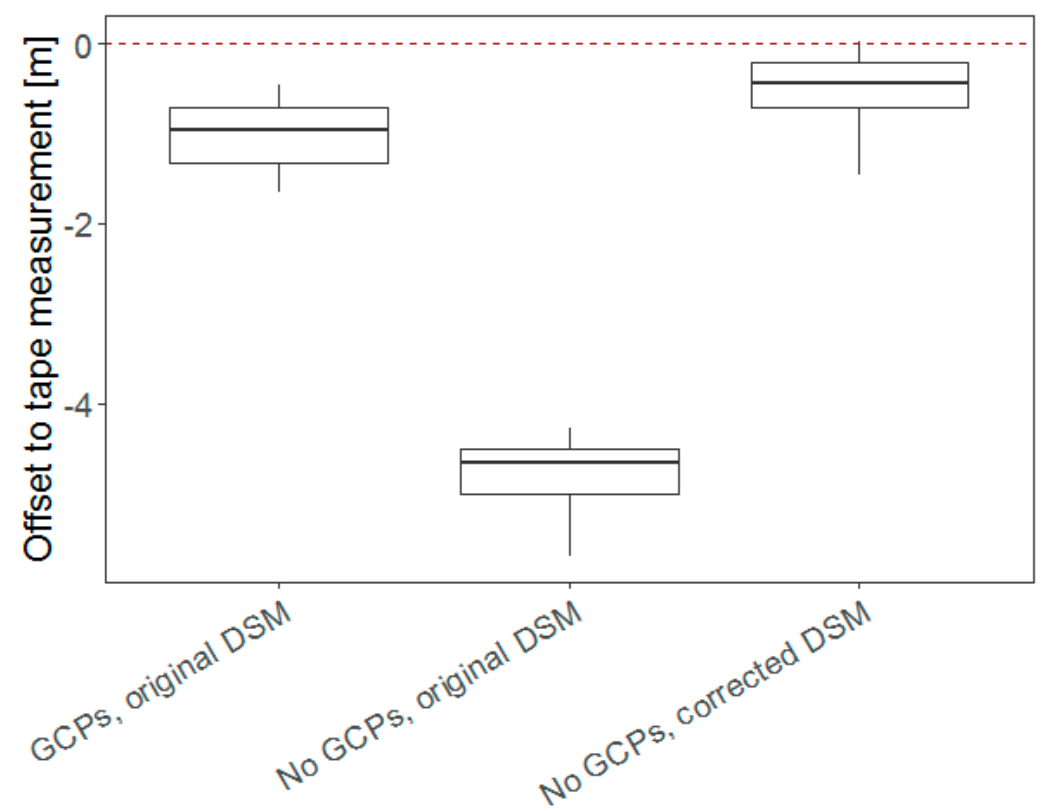

Figure 7. Boxplot analysis to investigate the effect of orientation quality on tree height measurements. The analysis was carried out with the dataset unmanned aerial vehicle (UAV)-Camera 2017 both with and without ground control points (GCPs). Calculations of tree height without GCPs were carried out both with the original digital surface model (DSM) and with the retrospectively corrected DSM.

\section{Discussion}

In this study, we showed that the usage of remote-sensing-based methods for the derivation of tree heights partially lead to higher accuracies than traditional indirect field measurements. Indirect measurements via Vertex clinometer had a higher offset and tended to result in a larger error range 
compared to remote-sensing-based measurements. In general, field measurements of tree height using triangulation methods are labor-intensive and can result in errors of 1-5 m or more, largely due to the limited visibility of the very top of the tree from the ground [26-28]. Furthermore, the measurements can be biased with a human-related systematic error. This highlights the fact that traditional tree height measurements are estimations in turn [19]. Ref. [29] determined the degree of precision of tree height measurements with a Vertex clinometer and obtained a standard deviation of $0.5 \mathrm{~m}$ when measured 319 sample trees (pine, spruce, birch) with four trained mensurationists. Ref. [19] reported an RMSE ranging from approximately 1 to $2 \mathrm{~m}$ for larch, spruce, and pine. We obtained tree height measurements with an RMSE of $1.02 \mathrm{~m}$ with a ME of $-0.66 \mathrm{~m}$ for Douglas fir using a Vertex clinometer, meaning that tree height was underestimated probably because the tops of the trees were not recognized. The large error range indicates that accuracy varied according to the individual shape of a tree or treetop visibility. Ref. [18] obtained a similar RMSE of approximately 0.3 $\mathrm{m}$ with field-based and photogrammetric tree height measurements. In contrast to our results, ref. [18] observed an overestimation when measuring tree height indirectly using a Vertex clinometer. The study of ref. [19] revealed similar results: Tree height estimations using a laser scanner were closer to real tree heights than the traditional field-based survey.

With the tested remote sensing techniques, different tree heights were calculated for each individual tree, resulting in a wide range of accuracies. The aircraft image flights differ only in terms of point cloud density. Considering the relative error results of the aircraft data, it can be observed that the dataset with the higher point density provided the higher accuracy. Similar conclusions can be drawn about the gyrocopter flights. Here, the parameters flight altitude, image overlap, and point density changed. A lower altitude and a higher resulting point density lead to higher accuracy.

Between the UAV-Camera flights in our study in 2017 and 2018, there were significant differences in tree height. These differences were likely due to the limited number and distribution of GCPs during the 2017 flight. In 2017, four GCPs were implemented and orientation was difficult, in the following year 12 GCPs were implemented, distributed over the flight area. Furthermore, the analysis of the usage of GCPs and retrospective correction of the DSMs clearly showed that the use of GCPs could only improve the derivation of tree height to a limited extent. Without the usage of GCPS during image orientation and with a subsequent co-registration of DSM and DTM, the highest accuracy could be achieved. The accuracy strongly depends on the quality of the GCPs. Inaccurate GCPs can lead to greater errors. Therefore we support the recommendation of ref. [19] to improve image orientation by increasing the number of GCPs and to use repeated field-based measurements to obtain a more reliable accuracy assessment of remote sensing data. Another possibility for improving the image orientation is to improve the direct orientation of the UAV image data, for instance by real-time correction of the GNSS signal during the UAV flight.

The LiDAR datasets from 2017 and 2018 received approximately the same accuracies. The data from 2017 achieved slightly better accuracies with a higher flight altitude, a smaller overlap and a less dense point cloud in comparison to the LiDAR data from 2018. However, when comparing the 2017 and 2018 data, it needs to be mentioned that the reference data are different, which may also have an influence on the results.

Tree height measurements from UAV derived LiDAR, and photogrammetric data with an accurate orientation resulted in the lowest deviations. LiDAR and photogrammetric measurements resulted in a similar level of error, though LiDAR performed slightly better than photogrammetric based measurements. The use of aerial photography is, therefore, regarded as an adequate and cost-effective alternative for the measurement of individual crowns. As a consequence, the flexible UAV technology together with fully automated photogrammetric processing can be deployed for operational use [30]. However, the availability of a DTM is crucial when deriving tree height with photogrammetric data [17,24,31]. In ref. [17] digital aerial photogrammetry data have been proven accurate and cost-effective for the derivation of tree heights via an area-based approach where high accuracy ALS-derived DTMs exists. The overall findings of ref. [17,31,32] indicated that the performance of 
digital aerial photogrammetry is as good as ALS concerning the derivation of individual tree heights or canopy heights.

For tree height estimation with LiDAR technology, studies report an RMSE of $0.92 \mathrm{~m}$ using a UAV [33] and $1.2 \mathrm{~m}$ using an airplane as a platform [13]. With aerial photogrammetry on UAVs, an RMSE of $0.28 \mathrm{~m}$ [30], $0.35 \mathrm{~m}$ [34], $1.30 \mathrm{~m}$ [33], $1.38 \mathrm{~m}$ [35] and 3.00-3.08 $\mathrm{m}$ [36] was reached. Determining the canopy height by means of aerial photographs ref. [37] obtained an RMSE of $0.91 \mathrm{~m}$. These results indicate that accuracies depend on various factors: The remote sensing system, data acquisition, and processing as well as the type of reference data. The listed studies serve as examples and do not cover all publications currently published at the current time. The achieved accuracies of the present study are approximately in the same range and can give indications of which factors influence the accuracy of the derivation of tree height. All studies mentioned, except the studies by ref. [18,19], used indirect field measurements for validation. According to ref. [18,19], the magnitude of errors (RMSE) is reduced if direct field measurements are used for validation.

The data quality of DSMs is highly depended on data acquisition and processing parameters [38]. In this study, we controlled the following factors that may influence the accuracy of tree height derivation: Reference data (measurement method, tree species, forest type), illumination conditions during the flights in 2017, Image-matching parameters and algorithms to obtain DSM and tree height. Remaining influencing factors might be: Flight altitude, sensor type, platform, overlap, camera lens angle and orientation quality. Ref. [39] described a decreasing accuracy for the derivation of tree height with decreasing LiDAR point density or increasing flight altitude, whereby the flight altitudes 400, 800, and $1500 \mathrm{~m}$ above ground were tested. However, in the study of [40], only 1 of 54 LiDAR altitude metrics varied significantly between altitudes of $530-540 \mathrm{~m}$ and $840-850 \mathrm{~m}$ above ground. With the datasets of this study a high accuracy of RMSE $<1 \mathrm{~m}$ could be achieved with point densities $>$ 350 points $/ \mathrm{m}^{2}$. Ref. [19] obtained with LiDAR data containing $10 \mathrm{pulses} / \mathrm{m}^{2}, 5 \mathrm{pulses} / \mathrm{m}^{2}$ and $1 \mathrm{pulse} / \mathrm{m}^{2}$ an RMSE of $0.76,0.97$, and $1.11 \mathrm{~m}$ in comparison to direct field measurements. Ref. [41] tested multiple configurations of altitude, GSD and image overlap. The results showed that lower flight altitudes (1200 $\mathrm{m}$ versus $4800 \mathrm{~m}$ above ground level) generated denser point clouds but did not improve tree height estimates. Similar results found in ref. [42] using ALS. In order to characterize leading forest cohorts, ref. [43,44] found GSDs of $30-40 \mathrm{~cm}$ provided surface models sufficient. However, ref. [45] highlighted that the relationship between camera lens angle and flight altitude can result in a decreasing accuracy of height predictions. They noted that while short focal length with wide angles offers a higher overlap, especially at greater altitudes, point clouds will suffer from occlusion problems and become less accurate in estimating tree heights. Similar results found in ref. [38]: The angle of view which depends on focal length and image overlap is important for the derivation of a DSM. According to ref. [38], a long focal length is more suitable for the derivation of DSMs in forests due to a minor radial displacement within the images and therefore a minor treetop displacement for trees located off-nadir. Furthermore, the GSD is a very decisive fact for the result of DSM [38].

After all various comparisons, not all influencing factors could be evaluated individually. In agreement with ref. [17], further research and development of data acquisition parameters are needed. To benchmark data acquisition parameters by the comparison of different studies, ref. [17] summarized various photogrammetric methods for updating area-based forest inventories.

\section{Conclusions}

The aim of this study was to compare methods for the measurement of individual tree heights. These consisted of two field-based measurement methods as reference measurements and various remote-sensing-based methods. From these comparisons, we identified factors influencing the accuracy in order to obtain reliable tree height measurements. These factors are an accurate orientation of the remote sensing data as well as a high point cloud density. However, we cannot quantify the influence of each factor, as they are affecting each other and may be influenced by site circumstances. Taking into account that this study worked within one test site only, which has a moderate slope, 
50-years-old Douglas Fir with varying crown closure, the following conclusions can be drawn. Overall, all remote sensing techniques could be used for deriving heights of individual trees. In this study, with low flight altitudes, small camera lens angles, and an accurate orientation, higher accuracies for the estimation of individual tree heights could be achieved. This leads to the general assumption that a point cloud with high quality and density in combination with an accurate orientation are optimal conditions for the derivation of reliable tree heights. If the aforementioned conditions are fulfilled, remote sensing measurements of tree height can be more accurate than traditional triangulation techniques. The study of [19] revealed similar results: Tree height estimations using a laser scanner were closer to real tree heights than the traditional field-based survey. We agree with ref. [19] to consider traditional measurements as essential, but to encourage an increasing awareness of their accuracy. We recommend using a remote sensing system fitting to the respective application, e.g., needed accuracy, temporal and spatial resolution, and available budget for the acquisition costs. The use of image-based data over areas of moderate to high canopy cover sets the pre-condition that a highly accurate DTM is available [24,46,47]. However, an accurate absolute orientation is crucial for all remote sensing techniques.

Author Contributions: Funding acquisition, P.A.; conceptualization and project administration, P.A. and S.G.; formal analysis and visualization, S.G. and Y.K.; writing the original draft, S.G., P.A. and Y.K.

Funding: This research was funded by the Federal Ministry of Food and Agriculture, grant number 22023114.

Acknowledgments: We would like to thank our colleagues from the Department for Forest Utilization of the FVA for the contribution to funding acquisition, conceptualization and project administration as well as for collecting the field data. We thank the Department for Forest Growth for enabling us to use the test site. Furthermore, we also thank Spectair GmbH \& Co. KG and the Fraunhofer Institute for High Frequency Physics and Radar Techniques FHR for carrying out the UAV and gyrocopter flights and for preprocessing the data.

Conflicts of Interest: The authors declare no conflict of interest.

\section{References}

1. Goodbody, T.R.; Coops, N.C.; Marshall, P.L.; Tompalski, P.; Crawford, P. Unmanned aerial systems for precision forest inventory purposes: A review and case study. For. Chron. 2017, 93, 71-81. [CrossRef]

2. Andersen, H.-E.; Reutebuch, S.E.; McGaughey, R.J. A rigorous assessment of tree height measurements obtained using airborne lidar and conventional field methods. Can. J. Remote Sens. 2006, 32, 355-366. [CrossRef]

3. Bragg, D.C. Accurately measuring the height of (real) forest trees. J. For. 2014, 112, 51-54. [CrossRef]

4. Fieber, K.D.; Davenport, I.J.; Tanase, M.A.; Ferryman, J.M.; Gurney, R.J.; Becerra, V.M.; Walker, J.P.; Hacker, J.M. Validation of canopy height profile methodology for small-footprint full-waveform airborne lidar data in a discontinuous canopy environment. ISPRS J. Photogramm. Remote Sens. 2015, 104, 144-157. [CrossRef]

5. Silva, C.A.; Hudak, A.T.; Vierling, L.A.; Loudermilk, E.L.; O’Brien, J.J.; Hiers, J.K.; Jack, S.B.; Gonzalez-Benecke, C.; Lee, H.; Falkowski, M.J. Imputation of individual longleaf pine (Pinus palustris mill.) tree attributes from field and lidar data. Can. J. Remote Sens. 2016, 42, 554-573. [CrossRef]

6. Waser, L.T.; Boesch, R.; Wang, Z.; Ginzler, C. Towards automated forest mapping. In Mapping Forest Landscape Patterns; Springer: New York, NY, USA, 2017; pp. 263-304.

7. Dean, T.J.; Cao, Q.V.; Roberts, S.D.; Evans, D.L. Measuring heights to crown base and crown median with lidar in a mature, even-aged loblolly pine stand. For. Ecol. Manag. 2009, 257, 126-133. [CrossRef]

8. Jung, S.-E.; Kwak, D.-A.; Park, T.; Lee, W.-K.; Yoo, S. Estimating crown variables of individual trees using airborne and terrestrial laser scanners. Remote Sens. 2011, 3, 2346-2363. [CrossRef]

9. Kato, A.; Moskal, L.M.; Schiess, P.; Swanson, M.E.; Calhoun, D.; Stuetzle, W. Capturing tree crown formation through implicit surface reconstruction using airborne lidar data. Remote Sens. Environ. 2009, 113, 1148-1162. [CrossRef]

10. Luo, L.; Zhai, Q.; Su, Y.; Ma, Q.; Kelly, M.; Guo, Q. Simple method for direct crown base height estimation of individual conifer trees using airborne lidar data. Opt. Express 2018, 26, A562-A578. [CrossRef]

11. Muss, J.D.; Mladenoff, D.J.; Townsend, P.A. A pseudo-waveform technique to assess forest structure using discrete lidar data. Remote Sens. Environ. 2011, 115, 824-835. [CrossRef] 
12. Popescu, S.C.; Zhao, K. A voxel-based lidar method for estimating crown base height for deciduous and pine trees. Remote Sens. Environ. 2008, 112, 767-781. [CrossRef]

13. Solberg, S.; Naesset, E.; Bollandsas, O.M. Single tree segmentation using airborne laser scanner data in a structurally heterogeneous spruce forest. Photogramm. Eng. Remote Sens. 2006, 72, 1369-1378. [CrossRef]

14. Vauhkonen, J. Estimating crown base height for scots pine by means of the 3D geometry of airborne laser scanning data. Int. J. Remote Sens. 2008, 31, 1213-1226. [CrossRef]

15. Wallace, L.; Watson, C.; Lucieer, A. Detecting pruning of individual stems using airborne laser scanning data captured from an unmanned aerial vehicle. Int. J. Appl. Earth Obs. Geoinf. 2014, 30, 76-85. [CrossRef]

16. Xu, W.; Su, Z.; Feng, Z.; Xu, H.; Jiao, Y.; Yan, F. Comparison of conventional measurement and lidar-based measurement for crown structures. Comput. Electron. Agric. 2013, 98, 242-251. [CrossRef]

17. Goodbody, T.R.; Coops, N.C.; White, J.C. Digital aerial photogrammetry for updating area-based forest inventories: A review of opportunities, challenges, and future directions. Curr. For. Rep. 2019, 5, 55-75. [CrossRef]

18. Krause, S.; Sanders, T.G.; Mund, J.-P.; Greve, K. Uav-based photogrammetric tree height measurement for intensive forest monitoring. Remote Sens. 2019, 11, 758. [CrossRef]

19. Sibona, E.; Vitali, A.; Meloni, F.; Caffo, L.; Dotta, A.; Lingua, E.; Motta, R.; Garbarino, M. Direct measurement of tree height provides different results on the assessment of lidar accuracy. Forests 2017, 8, 7. [CrossRef]

20. Abetz, P. Douglasien-standraumversuche. AFZ Wald 1971, 26, 448-449.

21. Husch, B.; Beers, T.W.; Kershaw, J.A., Jr. Forest Mensuration, 4th ed.; John Wiley \& Sons, Inc: Hoboken, NY, USA, 2003.

22. Landesamt für Geoinformation und Landentwicklung Baden-Württemberg L Geobasisdaten. 19 January 2018. Available online: www.lgl-bw.deaz.:2851.9 (accessed on 15 August 2019).

23. Roussel, J.-R.; Auty, D. lidR: Airborne Lidar Data Manipulation and Visualization for Forestry Applications. R package version 1.5.0. 2018. Available online: https://rdrr.io/cran/lidR/ (accessed on 15 August 2019).

24. White, J.; Wulder, M.; Vastaranta, M.; Coops, N.; Pitt, D.; Woods, M. The utility of image-based point clouds for forest inventory: A comparison with airborne laser scanning. Forests 2013, 4, 518-536. [CrossRef]

25. Landesamt für Geoinformation und Landentwicklung Baden-Württemberg (LGL). Digitale Geländemodelle (dgm). Available online: https://www.lgl-bw.de/lgl-internet/opencms/de/05_Geoinformation/ Geotopographie/Digitale_Gelaendemodelle/ (accessed on 9 July 2019).

26. Bragg, D.C. An improved tree height measurement technique tested on mature southern pines. South. J. Appl. For. 2008, 32, 38-43.

27. Goetz, S.; Dubayah, R. Advances in remote sensing technology and implications for measuring and monitoring forest carbon stocks and change. Carbon Manag. 2011, 2, 231-244. [CrossRef]

28. Larjavaara, M.; Muller-Landau, H.C. Measuring tree height: A quantitative comparison of two common field methods in a moist tropical forest. Methods Ecol. Evol. 2013, 4, 793-801. [CrossRef]

29. Luoma, V.; Saarinen, N.; Wulder, M.; White, J.; Vastaranta, M.; Holopainen, M.; Hyyppä, J. Assessing precision in conventional field measurements of individual tree attributes. Forests 2017, 8, 38. [CrossRef]

30. Birdal, A.C.; Avdan, U.; Türk, T. Estimating tree heights with images from an unmanned aerial vehicle. Geomat. Nat. Hazards Risk 2017, 8, 1144-1156. [CrossRef]

31. Ullah, S.; Dees, M.; Datta, P.; Adler, P.; Schardt, M.; Koch, B. Potential of modern photogrammetry versus airborne laser scanning for estimating forest variables in a mountain environment. Remote Sens. 2019, 11, 661. [CrossRef]

32. White, J.C.; Coops, N.C.; Wulder, M.A.; Vastaranta, M.; Hilker, T.; Tompalski, P. Remote sensing technologies for enhancing forest inventories: A review. Can. J. Remote Sens. 2016, 42, 619-641. [CrossRef]

33. Wallace, L.; Lucieer, A.; Malenovský, Z.; Turner, D.; Vopěnka, P. Assessment of forest structure using two uav techniques: A comparison of airborne laser scanning and structure from motion ( $\mathrm{sfm}$ ) point clouds. Forests 2016, 7, 62. [CrossRef]

34. Zarco-Tejada, P.J.; Diaz-Varela, R.; Angileri, V.; Loudjani, P. Tree height quantification using very high resolution imagery acquired from an unmanned aerial vehicle (uav) and automatic $3 \mathrm{~d}$ photo-reconstruction methods. Eur. J. Agron. 2014, 55, 89-99. [CrossRef]

35. Giftthaler, M. Ermittlung von einzelbaumhöhen basierend auf fernerkundungsdaten unbemannter luftfahrtsysteme. AGIT J. 2017, 3, 142-152. 
36. Panagiotidis, D.; Abdollahnejad, A.; Surový, P.; Chiteculo, V. Determining tree height and crown diameter from high-resolution uav imagery. Int. J. Remote Sens. 2017, 38, 2392-2410. [CrossRef]

37. Jensen, J.; Mathews, A. Assessment of image-based point cloud products to generate a bare earth surface and estimate canopy heights in a woodland ecosystem. Remote Sens. 2016, 8, 50. [CrossRef]

38. Bayer, S. Automatisierte Einzelbaumextraktion im Forst: Analyse und Optimierung von Aufnahmeparametern und Prozessierungsschritten von der Luftbildaufnahme bis zum Attributierten Einzelbaum. Ph.D. Thesis, Freie Universität Berlin, Berlin, Germany, 2018.

39. Yu, X.; Hyyppä, J.; Hyyppä, H.; Maltamo, M. Effects of flight altitude on tree height estimation using airborne laser scanning. Int. Arch. Photogramm. Remote Sens. Spat. Inf. Sci. 2004, XXXVI part 8/W2, 96-101.

40. Næsset, E. Effects of different flying altitudes on biophysical stand properties estimated from canopy height and density measured with a small-footprint airborne scanning laser. Remote Sens. Environ. 2004, 91, 243-255. [CrossRef]

41. Bohlin, J.; Wallerman, J.; Fransson, J.E. Forest variable estimation using photogrammetric matching of digital aerial images in combination with a high-resolution dem. Scand. J. For. Res. 2012, 27, 692-699. [CrossRef]

42. Lim, K.; Hopkinson, C.; Treitz, P. Examining the effects of sampling point densities on laser canopy height and density metrics. For. Chron. 2008, 84, 876-885. [CrossRef]

43. Honkavaara, E.; Litkey, P.; Nurminen, K. Automatic storm damage detection in forests using high-altitude photogrammetric imagery. Remote Sens. 2013, 5, 1405-1424. [CrossRef]

44. Honkavaara, E.; Markelin, L.; Rosnell, T.; Nurminen, K. Influence of solar elevation in radiometric and geometric performance of multispectral photogrammetry. ISPRS J. Photogramm. Remote Sens. 2012, 67, $13-26$. [CrossRef]

45. Gobakken, T.; Bollandsås, O.M.; Næsset, E. Comparing biophysical forest characteristics estimated from photogrammetric matching of aerial images and airborne laser scanning data. Scand. J. For. Res. 2015, 30, 73-86. [CrossRef]

46. Goodbody, T.; Coops, N.; Hermosilla, T.; Tompalski, P.; Pelletier, G. Vegetation phenology driving error variation in digital aerial photogrammetrically derived terrain models. Remote Sens. 2018, 10, 1554. [CrossRef]

47. Tomaštík, J.; Mokroš, M.; Saloň, Š.; Chudý, F.; Tunák, D. Accuracy of photogrammetric uav-based point clouds under conditions of partially-open forest canopy. Forests 2017, 8, 151. [CrossRef]

(C) 2019 by the authors. Licensee MDPI, Basel, Switzerland. This article is an open access article distributed under the terms and conditions of the Creative Commons Attribution (CC BY) license (http://creativecommons.org/licenses/by/4.0/). 